\title{
CHALLENGES OF HUMAN RESOURCE MANAGEMENT IN A VIRTUAL BUSINESS ENVIRONMENT
}

\author{
Jelena Đorđević Boljanović, \\ Gordana Dobrijević, \\ Filip Đoković
}

Singidunum University, Belgrade, Serbia

Correspondence:

Đorđević Boljanović Jelena

e-mail:

jboljanovic@singidunum.ac.rs

\begin{abstract}
:
As a result of ubiquitous information technologies (IT) and their growth in the modern business environment, a virtual business reality is very close to being part of everyday existence. It is up to organizations to identify their own recipe for success against this new business backdrop. That being so, more and more organizations tend to structure their individual functions as to make them more flexible and adaptable to change. One more implication is the need to adjust human resource management (HRM) to virtual business operations, based not only on the innovative reorganization of activities, usually IT-based, but also on the readiness of HR managers to employ a new approach to the standard issues - from leadership, teamwork, the development of required and necessary skills, to sometimes indispensable outsourcing of the very HRM function. The paper will discuss the impact of a virtual business environment on all aspects of the business process and efficiency of the HRM function.
\end{abstract}

Key words:

human resource management (HRM), virtuality, HR outsourcing.

\section{INTRODUCTION}

A virtual business environment is a fact of life. A workspace is defined by time zones, not walls; the boundary between work and home no longer exists. What might certainly give a boost to employee productivity is to give your employees a choice as to where and when they prefer to work. As if to make it possible, organizations have already accepted IT-based networks as a way to increase flexibility as one of the prerequisites for timely responses to frequent and permanent changes in the environment. Sara Sutton Fell, the founder and CEO of the Flex Jobs website that promotes distance work, says that 99 percent of employed people check their emails and phone calls wherever they are, while according to different outlooks a half of the workforce will be doingdistant work by 2020. A recent study by FlexJobshas identified 76 companies in different industries that opted for a work-from-home concept, involving all or nearly all of their employees (Vozza, S., 2015). Yet another proof that "the virtual" is already a part of everyday existence for a good part of the business community is the following list of industry leaders that have been using different types of flexible hours, flexible hiring and virtual operations (Lepore, M., 2014): Apple, Dell, Humana, American 
Express, Xerox, IBM, About.com, Microsoft, Thomson Reuters, Mozilla, Bausch\&Lomb, SAP, General Electric, Cisco Systems, Google, JetBlue, Citibank.

The inescapable conclusion is that doing business in a virtual reality sets a series of new requirements before an employer: to hire the right employee or professional, prepared to immerse in innovative technologies and shift from the traditional work concept to a flexible, virtual business environment; to recognize the traits of the upcoming generation of employees (the so-called Millennial Generation), to whom geographic parameters, the location or time, do not matter very much in doing a job; to identify the correct method of communication and a degree of flexibility to be applied on assignments and schedules; to recognize and use the advantages of new technologies. Given the above, the question arises as to what kind of a role the HRM function plays, and in what way this vital managerial segment needs to be transformed to make "the virtual" a hallmark of the environment in which HRM strategies, policies and procedures are implemented.

\section{HUMAN RESOURCE MANAGEMENT AND VIRTUALITY}

When it comes to virtual jobs, it is human resource management that strikes a balance between employers' concern that they won't be able to control their employees unless they are physically present and they can actually see them, and the need for flexibility as the sine qua nonof innovation, creativity and growing employee productivity.

Kevin Eikenberry and Wayne Turmel, the two authors of the Remote Leadership Institute (Tartell, R., 2015) have offered three-step directions to help virtual leaders. We believe them to be a good guide for HR managers as to how to exercise the leadership role they by all means have in modern organizations. The two authors suggest there are three key courses of action in virtual networks:

Leadership and management. A virtual business environment changes the context in which the connection between the leader and employees is created and maintained. The many advantages of face-to-face interaction are no longer available, and new, different elements are to be added to enrich communication. There is a very clear need for HR managers to provide more information on the given assignment or policy of the company than they would normally do when able to read non- verbal cues by their employees. Likewise, frequent and regular communication is as important as the selection of employees, based not only on their skills and knowledge, but also personal traits and the ability to adapt to a virtual job.

Technology and methods. Facebook, Twitter, WebEx, Skype and Face Time are just a few communication tools used by leaders and, by extension, HR managers. It is necessary to choose the right method of personal communication, relying largely on the personal empathy involved in the method, and, alternatively, its availability and the specter of influence.

Skills and influence. Low levels of proficiency in using technological tools and methods in a virtual business environment can only generate mediocre results. If participants in these new modes of communication are not concentrated enough, that can only add to the unwanted outcome. The recommendation is to create an environment that can largely recreate a face-to-face meeting. It is only a proper groundwork and good knowledge of the environment and co-workers that can make it happen. Another fundamental ingredient to add is the existence of common goals between HR managers and employees, as the only way to create a cohesive environment and determination to implement a corporate strategy.

Most authors believe there's a fourth aspect to be discussed - the organizational context, including formal structures and expectations within the organizations. (Tartell, R., 2015)

\section{TEAMWORK AND VIRTUAL TEAM MANAGEMENT}

It goes without saying that a virtual work environment implies virtual teams and the need to manage them. HR managers are the traditional leaders in their respective organizations, dealing with the challenges of managing the teams and guiding them to full efficiency on a daily basis. They are invariably serious, given the difficulties inherent to this category of teams - monitoring and evaluation of team results without a direct contact, different time zones, technological and cultural barriers, to name a few. Some researchers have found out that as many as one-fourth of virtual teams fail to meet the expectations. (Lepsinger, R. at al, 2015)

Practice has singled out the RAMP model, standing for Relationships, Accountability, Motivation and Process, designed to lead virtual teams. (Virtual Team Study Report, 2016) 
Relationships. It is very important to build relationships with the members of a virtual team, and take a proactive approach to building them. In a virtual work environment, it is often impossible to meet people personally, which is why the leaders and HR managers should do all that's necessary to build relationships based on mutual trust. It is not only the mutual trust, but also common goals and interests that can serve as the fundamentals of building these relationships, often relying on informal activities such as video chats, the so-called virtual coffee breaks or care calls, which require no official, pre-arranged agenda.

Accountability. Managing accountabilities in a virtual environment generates additional challenges, including limited opportunities for observing the work process directly and the question of employees' autonomy. Virtual workers often need to manage themselves, and account independently for the deadlines and the quality of their work. In spite of the restricted options for the managers to observe their employees, there are ways to manage accountability. Some of them rely on software, like Basecamp, Work Zone or Wrike, which can make an entire project visible to all members of the team, and give everyone a clear picture if and to what extent their work can fit into the master plan, more precisely, the project as a whole. Time Fox, Timesheet and Kronos software can improve the productivity of teams, allowing the team leaders - or more to the point, HR managers - to track hours and the time individual members of the team invested in the job. (Lepsinger, R. et al, 2015)

Motivation. The members of a virtual team often feel isolated, losing a sense of importance of the job they are doing. In order for the downside of the concept to be eliminated, and to motivate the employees working in a virtual work environment, it is necessary to foster constructive communication, active listening, clear presentation of goals, to ensure permanent availability of leaders and managers, often outside the business hours, and to use the tools like video conferences, Google Hangouts, Google Talk, Microsoft Lync (Skypefor Business) and Cisco Jabber, allowing for permanent contacts with the team members, but in a less formal way.

Process. It would be wrong to assume that new employees might already know how to use the programs or understand the processes used in the company. Instead, they need to be trained how to use virtual collaboration programs like Go To Meeting or Google Drive. Virtual leaders should have all the processes documented, and all the protocols and procedures available to the employ- ees, so that they can take part in all organizational processes. Corporate meeting software can lend a helping hand, including WebEx, once again Go To Meeting, then Adobe Connect and Polycom conferencing.

Most of HR managers might agree that a lion's share of their job has already switched to the virtual business context. John Cassida, a HR manager with the 40,000-strong Sprint Nexel, relying on the assistance of $46 \mathrm{HR}$ professionals, says that the virtual components of their work are already a part of standard routine. Sharing his opinion is E.J. Blanchfield, a Point BHR manager running a team of $24 \mathrm{HR}$ professionals, who do not necessarily work from an office to perform recruiting, professional development, compensations and benefits for 445 employees. (Krell, E., 2012) The two managers have underlined that managing performance, dealing with personal employee issues and materializing strategies are HR activities that can only benefit from personal contacts and in-person interaction. Even these activities can be conducted virtually, however, provided there's good leadership, a proper exchange of information and use of technology, the two managers have maintained.

A proof that the above arguments are in full correspondence with modern practices is a series of virtual HRM jobs that appeared on job search sites (Indeed. com) or social networks like LinkedIn: Virtual Human Resources Consultant, Senior Director of Talent, Virtual; Hospice Recruiter - Virtual; Virtual Corporate Contact Recruiter, Virtual Human Resource Consultant, Telecommute Human Resources Business Partner, Telecommute Human Resources Global Director.

\section{HR OUTSOURCING}

In addition to the above line of reasoning, practice has shown that small and medium-sized enterprises, as well as virtual companies with employees across the country, find virtual HR departments very attractive. If employees communicate via emails, Skype or other Internet technologies, the HR department needs to communicate the same way. As a matter of fact, the virtual companies offer the best example of feasibility and validity of outsourcing different business functions, including marketing, accounting, and more and more often, HR operations.(Hollister, J, 2015)

Speaking of outsourcing the HRM function, which many organizations have accepted, we need to list both the advantages and disadvantages of the process. (Armstrong, S., Mitchel, B., 2007) On the upside, HR professionals are more strategically oriented if routine opera- 
tions are outsourced. Efficiency is another argument in favor or outsourcing - if the organization the HR operations have been outsourced to is specialized in performing those operations precisely, it will certainly get more done, and in less time than the HR professionals in the department. The shortcomings of this type of work organization lie in the threatened privacy of an employer (some organizations might not approve of certain aspects of their work being known to outsiders); reaction by employees (some of them might feel less connected to the organization); and relations with employees (outsourcing service providers might not be able to handle delicate issues properly).

In terms of the advantages and disadvantages of HR outsourcing, for an organization to make the right decision as to whether this type of work organization is justified or not, it needs to ask a few questions: Can the time, resources and money spent on the assignments we want to outsource justify the decision? What kind of an impact will the outsourcing have on the employees? Who will be in charge of coordination with the outsourcing service provider, and what kind of effects on employee productivity can be expected? What criterion will be used to select the outsourcing service provider? Only after answering these and a number of other questions can the organization discuss and consider properly the outsourcing decision. (Đorđević Boljanović, J., Pavić, Ž., 2011)

According to the Forbes magazine, the companies preferring virtual business operations, a virtual HR function or the idea of outsourcing human resources, have the following advantages to discuss: (Biro, M., 2013)

The organization can concentrate on its core competences. Even though the result of any HR department is neither a product, nor a service, it takes a lot of time and energy to organize one. A large HR department requires considerable resources, permanent oversight and innovation, which is why many organizations decide to outsource this function.

HR outsourcing saves the money needed to run this managerial function. It also makes it possible for organizations to hire top-class experts they could never afford on a permanent basis. This type of virtual workforce will continue to maintain a strong presence and a very important role.

Improved compliance. HRM legislation is expanding, and a failure to respect the regulations entails increasingly serious sentences. If the regulations and compliance are delegated to a compliance specialist, a chance that your organization might break the rules is reduced to the absolute minimum.
Improved recruitment. Recruiting top talent today is an art; as such, it needs to be addressed by a specialized organization that placed it on the top of its priority list, instead of being just one of many HR assignments.

Access to the latest tools and technology. The most innovative service providers use the latest technology, including Data Mining, analytics, virtual workforce leadership, cloud technology and social media, in order to address the organization's specific needs most effectively.

According to the same source (Biro, M., 2013), the organization should be aware of the risk of handing over to an outsider one of the fundamentals of its competitive advantage. As a result, the people selected for a job might be at odds with the company culture, while some consultants cannot always look after the employees as carefully as their own HR department would have. Likewise, the hired talent might prove to be a poor fit in terms of the corporate business strategy. In a word, outsourcing has great potential, but a decision to integrate it in the organizational structure must be very careful, and well-thought-out.

\section{VIRTUAL HR PROCESS IN PRACTICE}

Even though the need for flexibility is a rule rather than an exception, the question is to what degree the leaders, managers and even HR mangers are prepared to constant availability and flexibility the paper has addressed. The Fast Company Magazine issued in February (Holmes, R., 2016) presented the results of a research carried out by CEO.com, showing that $61 \%$ of Fortune 500CEOs haven't joined social media, considering them a distraction. Given that two billion people are on social media as we speak, and the average user spends two hours a day on social platforms, that millennials watch more YouTube than TV, and three out of four consumers say that social media can shape their buying decisions, it's only logical to ask if the CEOs' position is valid and sustainable.

Adaptability is a necessity, and HR managers already have the tools to make their function more flexible and suitable for virtual business applications. What they can already do online is to perform a long string of duties falling within their competence - HR planning, recruiting, selection and training.

Below is a list of software applications used most frequently in HR practice for recruiting, selection and socialization, which many believe to be the critical stages 
of the HR process. They allow for flexibility of experts and specialists in a virtual business environment. (Compare recruiting management software, 2016):

Job Diva is a Web-based tool that has been used since 2003 for applicant tracking and synchronization with the organization's business operations and management system. It operates on mobile devices, including iPads. One of the key features is "Resume Search for Skills By Years of Experience," which saves the recruiter from manually reviewing a large number of resumes.

Bullhorn Staffing and Recruiting Software is one of the most popular applicant tracking and recruitment systems. It makes it possible for HR agencies and HR specialists in organizations to manage applicants' contacts, track candidates and fill the vacancies more effectively. The software can be adjusted to the needs of a company, and serve as a basis for business decisions by middle and top managers.

Greenhouse Softwareplatform goes beyond applicant tracking, and allows a company to run the entire hiring process. The recruitment software is a link between an organization's recruitment needs and the best talent hiring practices in the given industry. The Greenhouse strategy begins with tracking the right candidates from multiple sources, based on job requirements, data from external agencies and recommendations. The platform is built to optimize the company's recruiting process, but it also encourages the employees to help attract new candidates for the job, by sharing applications and job vacancy adds on social media. The platform defines a consistent interview process, allowing for objectivity in comparing the candidate's advantages and weaknesses. A structured interview process the platform advocates consists of a candidate's resume, contacts, instructions for the interview and a scale to gauge the feedback from the interview.

Workable is very useful recruitment software, replacing emails and tables with a candidate tracking system, monitoring their results. It creates simple job descriptions and employees' career pages. The advantage of Workable is that it keeps in one place profile searches, interviews, notes, communications, schedules, comments and analytics, organizing the entire HR process online and in the next five steps: Get a careers site, Get applicants, Track applicants, Interview candidates, Learn \& Improve. (Workable, 2016)

HR Onboard software is built to make the socialization process more effective. It helps companies run the recruitment and hiring process successfully, by facilitating the initial experience of a new hire and administrative HR operations. (HR Onboard, 2016)

\section{CONCLUSION}

A virtual work environment allows for different types of flexibility, from flexible hours to flexible employee engagements. Be it the functional or financial flexibility that arises from the need to adapt to changing business conditions, it is up to human resource management, a managerial function that manages the most valuable assets of an organization - the employees, their talents, knowledge and skills - to meet the requirements.

The practice has shown, and the authors proved in this paper, that there's no universal way to do it. Instead, it is up to the organization to choose, and offer arguments to support the choice of a method to reach a desired level of flexibility. A leadership style, required skills and the effect to be made, the technology and methods to be used are also shaping the decision.

The conclusion is that a virtual business, too, needs to foster positive relations with employees, set clear, inspiring goals and adjust them to the business strategy. Supported by a proper IT choice and software applications available to HR managers, virtuality can be placed within a framework of humane, motivating work environment, which is the ultimate goal of the HRM philosophy.

\section{REFERENCES}

Armstrong, S., Mitchel, B. (2007) The Essential HR Handbook. A Quick and Handy Resource for Any Manager or HR Professional, Career Press, pages 173 - 174.

Biro, M.M. (2013) Top 5 Reasons HR Is On The Move, Forbes, available onhttp://www.forbes.com/sites/ meghanbiro/2013/12/01/top-5-reasons-hr-is-on-themove/\#ff3ba7a63b8e, entry taken on March 1, 2016.

Compare recruiting management software (2016), available onhttp://www.softwareadvice.com/hr/recruiting-software-comparison/, entry taken on March 3, 2016.

Đorđević Boljanović, J., Pavić, Ž. (2011) Osnove menadžmenta ljudskih resursa, Univerzitet Singidunum, Beograd, pages 23-24.

Hollister, J. (2015) Human Resource Goes Virtual, available onhttp://www.leagueofpower.com/weekend-businessblueprint/human-resources-goes-virtual-2/, entry taken on March 1, 2016.

Holmes, R. (2016) Yes, even CEOs need to use social media - and they need to do it well, Magazine Fast Company, February 2016, available on http://www.fastcompany. com/3056970/the-future-of-work/yes-even-ceosneed-to-use-social-media-and-do-it-well 
HR Onboard, Create great onboarding experiences, available onhttps://hronboard.me/, entry taken on March 8, 2016.

http://www.indeed.com/q-Virtual-Human-Resources-jobs. html

Krell, E, (2012) When HR teams work Virtually, HR Magazine, September 2012, page 81.

Lepore, M. (2014)50 of the Best Companies Hiring Remote Workers, October 30th, 2014, available onhttp://skillcrush.com/2014/10/30/50-companies-hiring-remote/, entry taken on March 1, 2016

Lepsinger, R., De Rosa, D, (2015) How to lead an effective virtual team, Ivey Business Journal, May - June 2015., available on http://iveybusinessjournal.com/how-tolead-an-effective-virtual-team/, entry taken on February $25,2016$.
Tartell, R. (2015) Virtual Leadership - Closing the Distance, Training, May - June, 2015, available onwww.trainingmag.com, entry taken on December 24, 2015.

Virtual Team Study Report, available onhttp://cdn2.hubspot.net/hub/425573/file-2239300834-pdf/Documents/OnPoint_Virtual_Team_Study_Report. pdf? $t=1421338433772$, entry taken on February 25, 2016.

Vozza, S.,(2015) How a company works when $100 \%$ of the staff is virtual, Fast Company, May 20, 2015., available on http://www.fastcompany.com/3046333/the-newrules-of-work/how-a-company-works-when-100-ofthe-staff-is-virtual, entry taken on November 15, 2015.

Workable, The 5 steps of hiring, available onhttps://www. workable.com/hiring-process, entry taken on March 8, 2016. 